\title{
'If they Can't Stand the Heat ...': Supporting the Academic Development of Higher Education Students with Anxiety and Depression Disorders
}

\author{
Marie Stevenson*
}

\author{
Learning and Teaching Unit, Magill Campus, University of South Australia, GPO Box 2471, Adelaide, SA 5000, \\ Australia
}

\begin{abstract}
Increasing numbers of university students live with psychiatric or mental disabilities. Two of the most common categories of mental disorder are anxiety and depression. It is commonly assumed that the support for these students is provided by mental health practitioners such as counselors. However these disorders have an impact on the students' learning and there is a role for those engaged in teaching at university (lecturers, tutors, and academic language and learning advisers) in supporting these students. This entails having some understanding of the effects of anxiety and depression on students' learning and of the effects of the still pervasive prejudice against those with mental disorders. A number of strategies are suggested that teachers can use in responding to the learning needs of students with anxiety and depression. These strategies have been used successfully for some years in a large Australian university.
\end{abstract}

Keywords: Anxiety, depression, academic advising, learning support.

\section{INTRODUCTION}

Studies of the retention, academic progression and needs of higher education students with psychiatric disabilities are relatively few. Studies suggesting ways to facilitate the learning of this group are even rarer. Among the reasons for this are that it is generally assumed that any support these students need falls in the domain of mental health practitioners and disability professionals. Another reason is that students in this group frequently do not want to make their conditions public for fear of being regarded as 'different' or even 'difficult'. These two factors are symptomatic both of the medicalization of psychiatric illnesses in Western societies (that is, an emphasis on medically driven classification, detection and treatment) and of the persistent stigma attached to them. However, there is a role for university teaching staff (lecturers, tutors, and academic language and learning advisers) in supporting the academic development of students with psychiatric disabilities. This paper suggests a number of strategies that university teachers can use to support the academic work of students with psychiatric disabilities. As a background to and demonstration of the need for these strategies, the incidence of mental disorders among university students, the effects these disorders can have on their studies, and the significant issue of the stigma associated with mental illnesses, will first be considered.

The terminology surrounding mental health and disability is contested [1]. Rather than engage with this ongoing debate, the term "mental disorders" will be used throughout this paper. What constitutes a mental "illness" or disorder is itself a contentious subject, as shown by the debates that

*Address correspondence to this author at the Learning and Teaching Unit, Magill Campus, University of South Australia, GPO Box 2471, Adelaide, SA 5000, Australia; Tel: +61 88302 4078; Fax: +61 88302 4390;

E-mail: marie.stevenson@unisa.edu.au continue to surround the widely used diagnostic criteria in the American Psychiatric Association's Statistical Manual of Mental Disorders (DSM-IV). The DSM-IV defines a mental disorder as a:

clinically significant behavioral or psychological syndrome or pattern that occurs in an individual and that is associated with present distress (e.g., a painful symptom) or disability (i.e., impairment in one or more important areas of functioning) or with a significantly increased risk of suffering death, pain, or an important loss of freedom. In addition, this syndrome must not be merely an expectable and culturally sanctioned response to a particular event, for example, the death of a loved one. Whatever its original cause, it must currently be considered a manifestation of a behavioral, psychological, or biological dysfunction in the individual [2].

The focus for this paper will be anxiety and depression disorders mainly because these have been the most common mental disorders affecting the many students with whom I have worked over the past 20 years as an academic language and learning adviser in a large multi-campus Australian university. Anxiety and depression can occur as separate disorders, in combination, or in coexistence with other disorders and illnesses, such as autism spectrum disorders, acquired brain injuries, and anorexia nervosa, to name a few.

\section{THE INCIDENCE OF ANXIETY AND DEPRESSION} AMONG UNIVERSITY STUDENTS

It is difficult to obtain a complete picture of the incidence of anxiety and depression disorders amongst either the general and student populations because studies use different sampling methods, different definitions of the disorders, focus on different disorders, and use different methods of reporting. In Australia, the 2007 National Survey of Mental 
Health and Wellbeing found that $20 \%$ of Australian adults experienced a mental illness in any year, a percentage that equates to 3.2 million people. Of these, $14.4 \%$ had an anxiety disorder and $6.2 \%$ had an affective disorder [3]. Both anxiety and depression disorders are the most common mental disorders in the 18 to 44 age group and the age of onset for these disorders is between 17 and 25, with a trend to earlier onset [4-6]. Three quarters of those who experience mental disorders do so between 17 and 25 , a time when many young people are undertaking university study [1]. In America, there has been a significant rise over the past decade in the number of students who report a psychiatric disability as their primary disability [7]. Of more than 400,000 students in American postsecondary institutions who report having a disability, over 33,000 have a mental disorder [8]. In addition, $4.7 \%$ of college dropouts in America were persons with mental disorders, a percentage that equates to almost 5 million people [9].

These reports suggest that staff teaching in universities in Western cultures are likely to have significant numbers of students in their classes who are living with mental disorders, that the number could be as high as 1 in 6 students, and that the number is increasing. The students' circumstances will vary. Some will have entered university with an existing disorder, while some will experience the onset of a disorder during their time at university. Some will seek medical attention and be diagnosed, while some will not be diagnosed. Their disorders will also manifest in different ways. Some will experience acute episodes; for others their disorder will be chronic. For some their disorder will resolve spontaneously; for others it will resolve as a result of treatment, and for some it will not resolve at all.

\section{OTHER ISSUES RELATED TO MENTAL DISORDERS}

The dominant model of disability (both physical and mental) in both professional discourses (such as rehabilitative science, medical sociology and the biomedical sciences) and lay discourses is a medical one. Under this model the disability (whether mental or physical) is regarded as an "individual pathology" [10], as an "illness" located in the individual. Consequently, responses focus on how these deficiencies can be eliminated to make the individual "normal" or, if that is not possible, to treat or manage the illness [11]. This model of mental disorders is the most commonly subscribed to in the general community and, as part of that community, by teachers in higher education institutions [12]. A contrasting model is the social model of disability which focuses on the role of society in disability. Although it is not the only alternative to the medical model (e.g., the ecological model [13]), it does challenge the medical model directly and is useful to highlight its negative aspects and facilitate a shift beyond it.

The social model of disability was developed in Britain in the 1980s and 1990s by a number of disability activists including Colin Barnes, Mike Oliver and Len Barton [1416]. Central to this model is a distinction between impairment and disability. An impairment usually involves "a medically classified condition" [17] that has the potential to limit in some way the activities of the affected person. On the other hand a disability is the disadvantage or restriction of activity caused by a contemporary social organisation which takes no or little account of people who have ... impairments and thus excludes them from the mainstream of social activities [18].

In this model, disability is that which is socially created, through social structures or practices that disadvantage or exclude people with impairments through some restriction of their activities $[18,19]$.

The model shows that "existing social arrangements are neither natural nor proper and are therefore subject to critique and change" [20], that the restrictions and social disadvantage experienced by people with impairments are not inevitable, that they are "located spatially, temporally and economically" [19] and so they can be changed. It encourages an interrogation of the policies and procedures in institutions that may disadvantage or exclude people with impairments. It also offers a perspective from which those who work in institutions can reflect on their compliance or otherwise with such policies and practices.

However, to date, this social model appears to have had little impact on the overall approach to mental disorders possibly because a significant prejudice is still attached to these disorders. Living with a diagnosis of a mental disorder is, as one person expressed it a "double-edged sword; on the one hand it can legitimize the pain, but labels can be abused and negative attitudes can be attached like unwanted baggage" [1]. Physical illnesses and impairments may be accepted in a way that mental disorders are not because the "ontological status of mental illness is far more problematic" [17], that is; there is substantial uncertainty still about the nature of mental disorders. People diagnosed with mental disorders face a type of prejudice that manifests in the view that they have no impairment and are "just putting it on". To varying degrees the person with a mental disorder is commonly perceived as weak, malingering, self-indulgent or lacking in the will power to change his or her circumstances [21]. This is the basis of the "snap out of it", "pull your socks up" schools of psychiatric advice and comments about students such as "if they can't stand the heat (i.e. the stresses of study) then they should get out of the kitchen". This type of response has been part of my experience both as a teacher in higher education through comments made about students, and as someone who has lived with an anxiety/depression disorder for many years.

People with impairments look for explanations of them from the meanings that are available in their society "to help them make sense of what is happening" [10]. For those with mental disorders, these explanations are often unavailable or incomplete. The self-doubt that this entails can become a type of "internalized oppression" [11]. The stigma associated with mental disorders can also be internalized to such an extent that the person with the disorder lives with the selfsuspicion that they may be just weak and a malingerer. This in turn exacerbates the disorder itself, leading to situations where the shame associated with self-stigmatization "overrides even the most extreme symptoms" of the disorder [21]. It is important when working with students with mental disorders that teachers/advisers never underestimate "the power of fear and ignorance about psychiatric disability - it can be the biggest barrier to a student's success" [22]. 
Responses that are pitying, irritated, over-protective and patronizing can all be equally destructive [20].

\section{THE EFFECTS OF ANXIETY AND DEPRESSION DISORDERS ON STUDENTS' LEARNING}

Confirmation of the significant place that prejudice plays is shown in a number of Australian and American surveys of the concerns of university students with mental disorders. Among the most significant issues are stigmatizing treatment, such as labeling a student as "difficult" or as a "problem student" [17, 23-25] and issues surrounding confidentiality, trust and disclosure, such as discussing a student's situation with other staff or students without the student's permission $[23,24]$. Other issues are the disorders themselves and their effects [19], and the medications and their side effects [22]. The side effects of medication can be significant and include sedation, fatigue, restlessness, blurred vision, dizziness, tremors, and memory lapses [26]. These surveys have also identified the following as of concern to students with mental disorders: embarrassment or difficulty in asking for help $[8,19,22,23]$; navigating the bureaucracy of large institutions and personal isolation [24]; difficulties with negotiation in the education environment and culture [26]; lack of co-ordination between service providers; hospitalization and its consequences [25]; regular attendance at classes; difficulty in understanding and correctly interpreting criticism; and difficulty in coping with unexpected changes $[17,22]$.

Issues specifically related to learning reported in these surveys include completing tasks in time frames [17, 24]; managing time and multiple tasks [1,8]; concentration, focusing attention and screening out environmental stimuli $[8,23]$; difficulties with short term memory [22]; loss of motivation $[22,26]$; and high levels of anxiety, especially exam anxiety $[8,22]$. The changes in cognitive functioning that are part of anxiety and depression disorders are the subject of on-going research in cognitive and neuropsychology. Problems with attention and concentration involve not only general attentional capacity but also selective attendance to stimuli, sustaining focus and redirecting attention [26]. Analogical, inductive and deductive reasoning can also be affected along with the ability to integrate information and analyze complex stimuli [26]. The negative effects of anxiety on working memory [27], on the ability to organize, store and retrieve information, and of depression on the retrieval and encoding of information into memory have been demonstrated particularly when a strong cognitive effort is required, such as at the beginning of a task [28].

\section{WORKING WITH STUDENTS WITH ANXIETY AND DEPRESSION}

The concerns of the students and the effects of anxiety and depression disorders have a direct bearing on the kinds and circumstances of the interventions that lecturers, tutors, and academic language and learning advisers can make. Many universities in Australia employ counseling and disability professionals to work with students. Some of the accommodations regularly made to support students with anxiety and depression disorders include extensions of time for assessments, alternative assessment arrangements, and alternative exam venues. However, because anxiety and depression can be episodic and unpredictable, and because of students' concerns about prejudice and confidentiality, students with anxiety and depression disorders may need support at times on an individual basis. Because of the nature of anxiety and depression disorders, they are also most likely to need support at a point when they are in some kind of crisis with their work, either overall, or with a particular assignment.

Lecturers with large classes may not feel able to offer individual support. However, in this position they can make sure that they are familiar with their institution's services for students with psychiatric disabilities and those who work in that area, and identify people to whom they can introduce the students. As one of the most frequent accommodations that students with anxiety and depression disorders require is more time for assessments, they can also ensure there is a system for extensions, if such arrangements do not already exist, which reduces the amount of self-advocacy the students need to undertake in their subject. As mentioned previously, students frequently feel ashamed and embarrassed about going "cap-in-hand" repeatedly to ask for extensions and, if affected by an episode of anxiety or depression, can find self-advocacy extremely difficult. This does not mean that lecturers should give extensions without some documentation of the impairment but that, it may be possible to develop an arrangement whereby, after seeing the documentation once, it is in place for the duration of the student's enrolment in that subject.

For those lecturers, tutors, and academic language and learning advisers who are able to work with students one-toone, it is not difficult to recognise when anxiety and/or depression are major blocks to a student's work. Excessive fatigue, sadness, irritation, feelings of failure and worthlessness, and/or guilt at being unable to manage an assignment may prevent a student from starting or completing an assignment. Alterations in cognition such as an insistent focus on details, slowed responses and difficulty in logical sequencing may inhibit their work or they may seem completely "frozen" with regard to their work. Facilitating the learning of students with anxiety and depression is concerned with creating a framework within which the student is sufficiently freed from internal and external impediments to be able to continue their work.

The other main goal when working with students with anxiety and depression is to implement strategies in such a way that the student will ultimately be able to implement them as self-management repertoires. All the strategies described below can be presented to students with overt reference to and commentary on the strategy itself. That said, recovery for many people with anxiety and depression can take a long time, often years, and the courage, persistence and sheer hard work they need to build a recovery is enormous. Those working with them need to be patient and encouraging and be prepared to work repeatedly with some students who appear repeatedly stuck in a similar place. Working with students with anxiety and depression requires an alertness and responsiveness to the students' state. On a "bad day", in mornings or after a change in medication, they may not be able to concentrate or focus for any length of time. In this situation the teacher/adviser can postpone a 
session, spread a session with the student over a number of days, or introduce breaks into the sessions.

The strategies described below have a "common sense" quality to them and do not require extensive training to implement. Nor are they applicable only for students with anxiety and depression. They have developed as responses to particular students' needs which, when successful, have been repeated with other students. With some refinements they have become a repertoire of responses that work. The criteria for their evaluation are that as a result of one of these interventions, students have been able to start or resume work and complete a particular assessment and/or course; that feedback on the strategies from individual students has been positive; and that the students are able to begin to use these strategies themselves.

The strategies are arranged into two main categories preventative strategies and other strategies. Other strategies are divided into organizational strategies, analytic strategies, unblocking strategies, and anxiety-reduction strategies. These are not distinct, mutually exclusive strategies and are used singly or in combination depending on the students' circumstances.

\section{Preventative Strategies}

These strategies are most often used with students who have disclosed a disorder and are able to discuss their study prior to the beginning of a teaching period. They are mainly aimed at preventing the difficulties students with anxiety and depression can have with managing time and multiple tasks, and completing tasks in time frames. They include:

- working with students to organize their study workload and to design a balanced relationship between their life, study and if relevant, paid work. Attention to this relationship may encourage some students to take a lighter study load or reduce their paid work load if possible.

- $\quad$ encouraging students to explore their preferred learning styles and introducing them to different learning techniques which can reduce anxiety and overcome procrastination. For example, using mindmapping can be a less demanding way of organizing ideas for a written assignment or presentation, for summarizing information and ideas from sources and for organizing information for learning for exams. Mind-mapping can be done by hand [29, 30] or by using available free software. Mind-maps present information in a simplified graphic form which facilitates integration, analysis and synthesis. However, being comfortable with new approaches to learning takes time and it is inappropriate to introduce these when a student is distressed.

- $\quad$ ensuring that students are aware of the people and resources available to them. It is important that lecturers, tutors and learning advisers build effective working relationships with those in the university who have responsibility for counseling and disability services. They can either seek the student's permission to talk to a counselor/disability adviser/learning adviser about their situation or preferably, with the student's permission, introduce them in person to the relevant people. This entails giving the students some idea of how that person might work with them. Students who disclose a mental disorder to a disability adviser in order to receive support may feel that an impersonal referral to a learning adviser insults their intelligence and capabilities unless they have a specific idea what aspect of their current circumstances the learning adviser can improve. Similarly, an impersonal referral by a learning adviser to a counselor or disability adviser can raise the spectre of the stigma surrounding mental disorders and disability. My own experience has been that students are far more likely to follow up with those who can support them after a personal introduction.

\section{Organizational Strategies}

Students with anxiety and depression can find it particularly difficult to organize their study workload. They often express concern that they are getting behind, are overwhelmed by the amount of work that they have to do, or have had a period where they have been unable to attend classes or be productive. Strategies in these situations include:

- mapping their assessments for the remainder of that period of study with them and developing a plan for completing their assessments including exams. This plan should include not only when each assessment is due but also when the preparation of each assessment item will begin. It is important that this joint negotiation of a work plan leads to a realistic plan the student feels is achievable. Missing additional deadlines can produce spiralling levels of anxiety and self-doubt.

- assisting with applications for extensions if the teacher/learning adviser does not have the power to grant them. A realistic work plan may show that there is a need to negotiate some alternative submission dates and if so, it is important to consider the impact that extensions for one or two assignments might have on the remainder of their workload to prevent a "snowballing" effect. As mentioned previously, the nature of anxiety and depression disorders is such that feelings of guilt or embarrassment or failure often make it extremely difficult for students to do their own advocacy at this stage.

- encouraging the student to monitor their progress. Once a work plan is in place, it is useful for the students to display it on a wall planner or similar, both as a guide and a reassurance. It is also useful for the students to regularly (for example, weekly) evaluate the plan and to suggest that they drop in at similar intervals to let the teacher/learning adviser know how effectively the plan is working.

\section{Analytic Strategies}

Students with anxiety and depression disorders, like many students, have problems with procrastination but often in a more extreme way such that they feel completely "frozen" with regard to their study. This in turn leads to an increase in anxiety and self-doubt. Procrastination gives 
some immediate relief to the level of anxiety being experienced so can be an attractive, often repeated option. A strategy in this situation involves

- $\quad$ working with the student to break the assignment process into a series of discrete steps that the student can focus on one at a time. The teacher/learning adviser then analyses the assignment task with the student and from that analysis, helps the student to develop a preliminary plan for the assignment, allocating approximate numbers of words to each section depending on the genre of the assignment (essay, report, etc). In this way, a formidable looking academic essay of 2,500 words becomes an introduction and a conclusion of 200 to 250 words each and a main "body" of 2,000 words which can be further broken down into four or five main ideas of 400 to 500 words each. Depending on the essay task it is often possible to anticipate the types of ideas required in the 'body' or at least to develop a strategy for searching for information. At this stage students often express tangible relief, as they now perceive the task as manageable.

- $\quad$ asking the student to write down the first two steps they will take to begin the assignment.

\section{Unblocking Strategies}

Students with anxiety and/or depression who seek help with an assignment are often blocked at one of two stages. The first is starting the assignment, where the analytic strategy above is effective, and the second is when a student has done sufficient, even extensive research, but cannot start to write. In the long term it is useful to show students who frequently get blocked at this stage, techniques for beginning to write while they are still researching and reading, so that "beginning to write" does not present as an obstacle. However, students often need a short-term solution to this problem. A strategy in this situation involves:

starting with the task the student has been set (the essay question, report task, etc.) and asking them to put aside all their notes and state in one or two sentences their possible response, or what position they want to take in relation to that task. Students often find this request difficult initially and want to consult their notes. With encouragement, they begin to trust what they have read and thought about and come up with a statement. The teacher/learning adviser then asks questions to get the student to expand on their two sentences and while the student talks the teacher/adviser takes brief notes of what they are saying, focusing on the logical organization of their ideas. The teacher/learning adviser then feeds back to the student what they have noted and asks them to confirm it. Then the student and teacher/adviser map these ideas onto the generic structure of the assignment (a research proposal, an essay, a report, a literature review, etc.). It is useful at this stage to hand the pen to the student so that they write the plan. At the conclusion of this process the student has a detailed plan of the assignment derived entirely from their research and understanding of the topic and in their own writing.

\section{Anxiety Reduction Strategies}

With students who are extremely distressed, it is sometimes necessary to encourage them to back away from their studies for a short period. A complete break (of 2 or 3 days) from working on an assignment and possibly from all their studies is often enough to allow the anxiety to diminish sufficiently for them to resume work. However, the students may also be anxious and agitated or guilty about taking "time out". A strategy in this situation involves:

- negotiating a "deal" with them. The student is asked to leave all the notes, books and resources they have been using to prepare the assignment with the teacher/learning adviser who agrees to take care of them while they forget about the assignment for however long has been discussed. This gives the student "permission" to back away from their study and the handover of materials is a kind of temporary handing over of responsibility. The teacher/ learning adviser also arranges a time to meet with the student so that they can collect the materials and resume work. The success of this strategy has been surprising. In every situation when such a "deal" has been made, the student has reappeared after 2 or 3 days ready to tackle the work again. As with previous strategies, it may be necessary to facilitate an extension of time for the student.

\section{CONCLUSION}

Increasing numbers of students in universities are living with and learning to live with mental disorders. As mentioned at the beginning of this paper, the years at university can coincide with the onset of these disorders for many young people. Learning to monitor and manage their disorder while continuing to participate fully in their studies is an enormous task. When discussing this with students, this has at times been referred to as their "second degree", a term which a number of students have themselves adopted. Health practitioners and disability professionals can and do provide aspects of the support and services that students need to persist and be successful with their studies. However, there will be times when students, affected by either the disorders themselves, and/or their medications may need to seek help from a lecturer, tutor or learning adviser on an individual basis. It is in this context that the strategies described in this paper can be applied. They can enable the student to move from a situation of extreme paralyzing anxiety towards a situation where they are able to be productive in their educational context.

The strategies outlined may seem obvious, "common sense", some even a little odd. However they directly address those aspects of the learning experience which students with anxiety and depression find most difficult. Episodes of anxiety and depression are self-consuming and all-consuming. Each of the strategies outlined entails some kind of "stepping back" from the immediate circumstances and a reflection on those circumstances from a broader or different perspective. For those experiencing episodes of anxiety or depression, this "stepping back" needs, at times, to be stimulated by an outsider interested in their learning. The strategies outlined in this paper both recognize these difficulties inherent in the circumstances of those 
experiencing anxiety and depression and acknowledge their persistence and courage in doing things that many people can take for granted. These strategies can enable them to step outside these states and regain a purchase on "ordinary student life".

\section{REFERENCES}

[1] McLean P, Andrews J. The learning support needs of students with psychiatric disabilities studying in Australian post-secondary institutions. South Australia: Australian National Training Authority 1999.

[2] American Psychiatric Association. Diagnostic and statistical manual of mental disorders 4th ed. Washington DC: American Psychiatric Association 1994.

[3] Australian Bureau of Statistics Mental Health Statistics Fact Sheet. 2007. [Retrieved October 7 2009]. Available from http://www. health.gov/internet/mentalhealth/publishing.nsf/Content/10416BD2 4115D987CA2573E00123DEA/\$File/MH\%20factsheet\%20April\% 2009.pdf

[4] Yapko MD. Breaking the bonds of depression. New York: Doubleday 1997.

[5] Henderson S, Andrews G, Hall W. Australia's mental health: an overview of the general population survey. Aust N Z J Psychiatry 2000; 34: 197-205.

[6] Smith-Osborne A. Antecedents to postsecondary educational attainment for individuals with psychiatric disorders: A metaanalysis. Best Pract Mental Health Int J 2005; 1: 15-30.

[7] Sharpe MN, Bruininks BD, Blacklock BA, Benson B, Johnson DM. The emergence of psychiatric disabilities in postsecondary education. Issue brief, 2004; 3(1). [Retrieved February 20, 2006]. Available from: http://www.ncset.org/publications/viewdesc.asp? id $=1688$

[8] Souma A, Rickerson N, Burgstahler S. Academic Accommodations for students with psychiatric disabilities. Seattle WA: Disabilities, Opportunities, Internetworking and Technology (DO-IT), University of Washington 2001.

[9] Kessler R, Foster C, Saunders W, Stang P. Social consequences of psychiatric disorders: educational attainment. Am J Psychiatry 1995; 152(7): 1026-32.

[10] Oliver M. A sociology of disability or a disablist sociology? In: Barton L, Ed. Disability and Society: Emerging issues and insights. Harlow, England: Prentice Hall 1996; pp. 18-42.

[11] Barnes C, Oliver M, Barton L. Introduction. In: Barnes C, Oliver M, Barton L, Eds. Disability studies today. Cambridge, UK: Polity Press 2002; pp. 1-17.
[12] Brett M, Kavanagh L. Reframing disability in higher education. Pathways 9 Conference 2008, Sofitel Melbourne. Available from: http:www.pathways9.org/abstract/15.asp

[13] Disability in higher education. Paris, France: Organisation for Economic Co-operation and Development (OECD) 2003.

[14] Barnes C, Mercer G, Eds. Exploring the divide: Illness and disability. University of Leeds, Leeds: Disability Press 1996.

[15] Barnes C, Oliver M, Barton L, Eds. Disability studies today. Cambridge, UK: Polity Press 2002.

[16] Barton L, Ed. Sociology and disability: Some emerging issues and insights. Harlow, UK: Prentice Hall 1996.

[17] Mulvany J. Disability, impairment or illness? The relevance of the social model of disability to the study of mental disorder. Sociol Health Illn 2000; 22(5): 582-601.

[18] Union of Physically Impaired Against Segregation (UPAIS), cited by: Oliver M. Defining impairment and disability: Issues at stake. In: Barnes C, Mercer G, Eds. Exploring the divide: Illness and disability. Leeds: Disability Press 1996; pp. 29-54.

[19] Thomas P. Disability theory: Key ideas, issues and thinkers. In: Barnes C, Oliver M, Barton L, Eds. Disability studies today. Cambridge, UK: Polity Press 2002; pp. 38-57.

[20] Barton L. Sociology and disability: Some emerging issues. In: Barton L, Ed. Disability and Society: Emerging issues and insights. Harlow, England: Prentice Hall 1996; pp. 3-17.

[21] Byrne P. Stigma of mental illness and ways of diminishing it. Adv Psychiatr Treat 2000; 6: 65-72.

[22] Smith P, Beebe H, Andrews A. Meeting the learner's needs: How TAFE can optimize the success of students who have a psychiatric disability. Proceedings of Pathways 6 Conference; 2002, Darling Harbour Conference Centre Sydney. Available from: http://www.adcet.edu.au/

[23] Weiner E, Weiner J. Concerns and needs of university students with psychiatric disabilities. J Postsecond Educ Disabil 1996; 12(1): 2-9.

[24] Weiner E. The meaning of education for university students with a psychiatric disability: A grounded theory analysis. Psychiatr Rehabil J 1999; 22(4): 403-9.

[25] Loewen G. Improving access to post-secondary education. Psychosocial Rehabil J 1993; 17(1): 151-5.

[26] McLean P, Bardwell M, Ryan J, Andrews J. A hidden disability: University students with mental health conditions. Melbourne, Australia: University of Melbourne 1998.

[27] Markham R, Darke S. The effects of anxiety on verbal and spatial task performance. Aust J Psychol 1991; 43(22): 107-11.

[28] Brand AN, Jolles J, Gispen-de Wied C. Recall and recognition memory deficits in depression. J Affect Disord 1992; 25(1): 77-86.

[29] Buzan T. Use your head. London: BBC Books 1989.

[30] Buzan T. The mind map book. London: BBB Worldwide 2003.

Received: June 30, 2009 